\title{
Rats Maintained Chronically on Buprenorphine Show Reduced Heroin and Cocaine Seeking in Tests of Extinction and Drug-Induced Reinstatement
}

\author{
Robert E Sorge', Heshmat Rajabi' and Jane Stewart*,' \\ 'Center for Studies in Behavioral Neurobiology, Department of Psychology, Concordia University, Montreal, QC, Canada
}

\begin{abstract}
Buprenorphine is being introduced as a maintenance therapy in opioid addiction, but it is not clear how buprenorphine will affect co-use of cocaine in opioid users. We examined the effects of chronic buprenorphine (BUPO: $0.0 \mathrm{mg} / \mathrm{kg} / \mathrm{day} ; \mathrm{BUPI} .5: 1.5 \mathrm{mg} / \mathrm{kg} / \mathrm{day} ; \mathrm{BUP3}$ : $3.0 \mathrm{mg} / \mathrm{kg} /$ day) on the locomotor activity effects of acute heroin $(0.25 \mathrm{mg} / \mathrm{kg}$, subcutaneously (s.c.)) and cocaine (20 mg/kg, intraperitoneally (i.p.)). Buprenorphine had no effect on the stimulatory effect of heroin, but potentiated the locomotor response to cocaine. To investigate further the interactions between buprenorphine (BUPI.5 and BUP3), heroin (0.125, 0.25 and 0.375 mg/kg, s.c.), and cocaine (10,20 and $30 \mathrm{mg} / \mathrm{kg}$, i.p.), we used in vivo microdialysis and high-performance liquid chromatography to analyze extracellular levels of dopamine (DA) in the nucleus accumbens (NAc). Buprenorphine attenuated the heroin-induced rise in NAc DA, but greatly potentiated the cocaine-induced rise. Finally, we examined the potential of the highest dose of buprenorphine (BUP3) to reduce heroin and cocaine seeking in the presence of drug-associated cues under extinction conditions and in tests for reinstatement induced by heroin $(0.25 \mathrm{mg} / \mathrm{kg}$, s.c.), cocaine $(20 \mathrm{mg} / \mathrm{kg}$, i.p.), and 15 -min footshock stress ( $0.8 \mathrm{~mA}, 0.5 \mathrm{~s} / \mathrm{shock}, 40 \mathrm{~s}$ mean OFF time) in rats trained to selfadminister both drugs. Buprenorphine reduced heroin and cocaine seeking during extinction and following acute heroin and cocaine priming injections, but had no effect on stress-induced reinstatement. These results indicate that the suppression of responding following priming injections of drugs did not result from reduced motor activity, but possibly from a reduction in the salience of drug-associated cues induced by chronic buprenorphine treatment.
\end{abstract}

Neuropsychopharmacology (2005) 30, I68 I- 1692. doi: I 0. I038/sj.npp. I 3007I2; published online 30 March 2005

Keywords: buprenorphine; heroin; cocaine; relapse; dopamine; microdialysis

\section{INTRODUCTION}

Co-abuse of cocaine by patients receiving treatment for opioid addiction often compromises the success of the pharmacological strategies. Cocaine use during treatment reduces retention rates and increases use of illicit drugs, reducing the effectiveness of the maintenance treatment drugs (Guichard et al, 2003; Kosten et al, 1987, 1988; Leri et al, 2003; Schottenfeld et al, 1993, 1997; Tassiopoulos et al, 2004). Thus, it is important to know how pharmacological treatments for opioid addiction interact with the response to cocaine and opioids and to the effects of cues associated with the self-administration of these drugs.

\footnotetext{
*Correspondence: Dr J Stewart, Center for Studies in Behavioral Neurobiology, Concordia University, SP-A-244, 7141 Sherbrooke St. W., Montreal, QC, Canada H4B IR6, Tel: + I 5 I4 848 2424ext.2193, Fax: + I 514848 2817, E-mail: jane.stewart@concordia.ca

Received 15 October 2004; revised 25 January 2005; accepted 27 January 2005

Online publication: I February 2005 at http://www.acnp.org/citations/ NPP020205040486/default.pdf
}

To date, the two opioid drugs most often in use in maintenance treatments are methadone and buprenorphine (Gonzalez et al, 2004; Kleber, 2003; Kosten, 1990; Krantz and Mehler, 2004). Both are agonists at the $m u$ opioid receptor, though there are fundamental differences in their actions. Methadone is a full $m u$ opioid receptor agonist, whereas buprenorphine is a partial $m u$ agonist with antagonist effects at the delta and kappa opioid receptors (Gonzalez et al, 2004; Tzschentke, 2002; Walsh and Eissenberg, 2003). Studies of the treatment effectiveness of maintenance doses of buprenorphine are few compared to those of methadone, and the results are mixed. However, on measures of retention rates and illicit opioid use, buprenorphine has been found to be as effective as, or better than, methadone when prescribed at higher doses $(8-16 \mathrm{mg} /$ day $)$ (Foltin and Fischman, 1996; Johnson et al, 1992; Kosten et al, 1988; Ling et al, 1996; Schottenfeld et al, 1997; Strain et al, 1994a, b, 1996), whereas lower dose regimens (2-4 mg/ day) are less effective (Greenwald et al, 2002; Ling et al, 1998; Montoya et al, 2004). Furthermore, there are reports that buprenorphine maintenance reduces craving for cocaine (Foltin and Fischman, 1996) and, to varying 
degrees, reduces cocaine consumption as measured by urine analysis in human opioid addicts (Johnson et al, 1992; Kosten et al, 1988; Ling et al, 1996; Schottenfeld et al, 1997; Strain et al, 1994a, b, 1996). In monkeys trained to selfadminister cocaine, heroin or heroin-cocaine 'speedball,' daily injections of buprenorphine have been found to reduce intake (Lukas et al, 1995; Mello and Negus, 1998; Mello et al, 1992, 1993) without changing the intake of food or sweetened fluid.

Many drugs of abuse increase extracellular dopamine (DA) in terminal regions including the nucleus accumbens (NAc), though by somewhat different mechanisms (Di Chiara and Imperato, 1988). As mentioned, buprenorphine is an agonist at the $m u$ opioid receptor; it has low intrinsic activity, high affinity, and slow dissociation from the receptor (Tzschentke, 2002; Walsh et al, 1994). Mu opioid agonists are thought to activate receptors on GABA interneurons in the ventral tegmental area (Garzon and Pickel, 2001), releasing DA neurons from inhibition and increasing firing rates. On the other hand, cocaine acts primarily to block the DA transporter reducing DA reuptake at terminals, thereby increasing extracellular levels of DA (Gysling and Wang, 1983; Matthews and German, 1984; Ritz et al, 1988, 1990; Rothman and Baumann, 2003; for a review, see Nestler, 2004). Consequently, it has been found in experiments using acute injections that both buprenorphine $(0.01 \mathrm{mg} / \mathrm{kg})$ and cocaine $(5.0 \mathrm{mg} / \mathrm{kg})$ increase extracellular levels of DA in the nucleus accumbens in rats (each approximately $180 \%$ of the baseline). As might be expected, an acute injection of buprenorphine given with an acute injection of cocaine produced an increase in DA in the NAc that was higher (approximately $260 \%$ of baseline) than that produced by that particular dose of either drug alone. This synergism was also reflected in the reinforcing effects of these drugs when they were administered together during the conditioning of a place preference (Brown et al, 1991). It is not clear how these results from studies using acute injections of buprenorphine can be related to those using chronic treatment with buprenorphine in human opioid addicts and in monkeys trained to self-administer opioids and cocaine. Interestingly, however, there is one report that twice daily injections of buprenorphine, which might be considered to be chronic treatment, attenuated the development of a cocaine conditioned place preference (CPP) (Kosten et al, 1991). As pointed out by Tzschentke (2004), however, the lack of CPP under such a regime might result from the fact that the dose used by Kosten and colleagues $(0.5 \mathrm{mg} / \mathrm{kg}$, twice daily) has been shown to produce a CPP on its own, thus confounding the establishment of the cocaine CPP; rats placed in the saline paired compartment would remain under the influence of a putatively rewarding dose of buprenorphine.

In this paper, therefore, we sought to resolve some of these issues by asking whether and how chronic treatment with buprenorphine alters the behavioral and neurochemical response to heroin and cocaine in naïve rats and drug seeking in rats trained to self-administer both heroin and cocaine. Spontaneous drug seeking was studied in extinction and in reinstatement of drug seeking induced by heroin, cocaine, and footshock stress. Buprenorphine was administered chronically through in-dwelling osmotic minipumps, allowing for continuous stable exposure to the drug for the duration of testing. In the first set of experiments, we studied the effects of acute injections of heroin and cocaine on locomotor activity and extracellular levels of DA in the NAc in rats with and without buprenorphine minipumps. These experiments helped to determine the dose to be used in the second set of experiments in which rats were trained to self-administer both heroin and cocaine. Following training, we studied heroin and cocaine seeking under chronic treatment with buprenorphine via minipump in two separate conditions: during extinction and in tests for reinstatement.

\section{MATERIALS AND METHODS}

\section{Subjects}

The subjects were 107 male Long-Evans rats (350-375 g, Charles River, St Constant, QC), housed singly in hanging wire cages in a reverse light-dark cycle room (light onset $2000 \mathrm{~h}$, offset $0800 \mathrm{~h}$ ). The rats had food (Rat Chow, Purina Foods) and water ad libitum for the duration of the experiment. Testing was conducted during the dark cycle between 0800 and $1700 \mathrm{~h}$. All experimental procedures followed the guidelines of the Canadian Council on Animal Care and were approved by the Animal Care Committee at Concordia University.

\section{Surgery-Osmotic Minipumps}

Chronic exposure to buprenorphine was achieved through the use of osmotic, buprenorphine-filled minipumps implanted subcutaneously (s.c.). Rats were anesthetized using Isoflurane (Vetoquinol NA Inc., Lavaltrie, QC) and a small incision was made between the scapulae. Using a hemostat, a small pocket was created by separating the connective tissues under the skin. Once the pocket was formed, osmotic buprenorphine-filled minipumps (Alzet model 2ML2, Durect Corp., Cupertino, CA) were implanted with the flow modulator pointed away from the incision to avoid leakage of the drug. The incision was closed using wound clips. Pumps were removed under anesthesia using the same surgical methods. In the case of the $0 \mathrm{mg} / \mathrm{kg} / \mathrm{day}$ buprenorphine (BUP0) rats, the same surgical procedures were employed, with the exception of the insertion of a pump (ie an incision and pocket were made and the wound was clipped following surgery).

\section{Surgery-Intracranial Cannulation}

The rats were anesthetized with sodium pentobarbital Somnotol $^{\mathrm{TM}}$, MTC Pharmaceuticals, Cambridge, ON; intraperitoneally (i.p.)) and then unilateral stainless steel 20gauge cannula (Plastics One, Roanoke, VA) were implanted aimed at the NAc (AP $+1.6 \mathrm{~mm}, \mathrm{ML}+2.8 \mathrm{~mm}$, DV $-5.5 \mathrm{~mm}$ from bregma) at an angle of $10^{\circ}$ in order to avoid extensive damage to the ventricle above the NAc, while maximizing the surface area of the probe within the NAc. Cannula were cemented in place with dental acrylic and the rats were placed in recovery following an injection of penicillin (Pen G, Vetoquinol, Lavaltrie, QC; intramuscularly (i.m.)) and Ketoprofen. 


\section{Surgery - Intravenous Catheterization}

For the self-administration and reinstatement experiment, the rats had intravenous catheters implanted in the right jugular vein. The rats were anesthetized with sodium pentobarbital (Somnotol ${ }^{\mathrm{TM}}$, i.p.) and given an s.c. injection of atropine sulfate (MTC Pharmaceuticals, Cambridge, ON) prior to surgery. The silastic (Dow Corning, Midland, MI) catheters were implanted and secured to the right jugular vein with silk sutures and passed s.c. to the top of the skull, where it was attached to a modified plastic cannula (Plastics One, Roanoke, VA) and fixed with jeweler's screws and dental cement to the skull surface. A plastic blocker was placed over the opening of the cannula (Tygon ${ }^{\mathrm{TM}}$ Tubing, Fisher Scientific, Montreal, QC) and protected from the rat with a metal cap. Following surgery, rats were injected with penicillin to prevent infection and Ketoprofen as postsurgery pain management. The blocker and cap were left in place at all times except when the rats were participating in self-administration, extinction, or reinstatement sessions. On every second day, following the self-administration sessions, the rats were flushed with $0.2 \mathrm{mg} / \mathrm{ml}$ heparinsaline solution (ICN Biomedicals, Cleveland, $\mathrm{OH}$ ).

\section{Apparatus}

Locomotor activity boxes. Locomotor activity was assessed in a bank of 12 activity boxes. Boxes were constructed of white pressed wood on three walls and clear Plexiglas for the front wall $\left(20 \times 41 \times 25 \mathrm{~cm}^{3}\right.$, custom-made, Concordia University). The top of the box was constructed of wire mesh, while the floor was evenly spaced stainless steel tubing. Two photocell pairs, positioned $3.5 \mathrm{~cm}$ from the floor, were located along the front and back walls of the chamber and provided a measure of horizontal locomotion. The bank of activity boxes was isolated in a room that was left in complete darkness for the duration of the testing. The photocells were connected, through a wall port, to a computer located in an adjacent room that ran the custom-made software.

\section{Microdialysis and High-Performance Liquid Chromatography}

Four hexagonal chambers were used for microdialysis. Each chamber $\left(42 \times 39 \times 33.5 \mathrm{~cm}^{3}\right.$, custom-made, Concordia University) consisted of Plexiglas walls with wooden ceilings and stainless steel grid floors. They were individually housed in wooden cubicles and lighting was provided on a reverse cycle by overhead lights.

Microdialysis probe. The dialysis probe (HRS Scientific, Montreal, QC) consisted of a $2.5 \mathrm{~mm}$ length of semipermeable dialysis membrane (Fisher Scientific, $240 \mu \mathrm{m}$ OD, $13000 \mathrm{MW}$ cutoff), closed at one end and attached to a $21 \mathrm{~mm}$ long, 26-gauge piece of stainless steel tubing. The flared end of a $40-50 \mathrm{~cm}$ long piece of PE tubing connected one end of the stainless steel shaft to a single-channel liquid swivel (HRS Scientific, Montreal, QC) stationed above the testing chamber that was, in turn, connected to a variable speed electric syringe infusion pump (Harvard Apparatus, South Natick, MA). Small-diameter fused silica tubing extended internally through the probe, with one end resting $0.5 \mathrm{~mm}$ from the tip of the probe and the other end exiting the PE tubing $35 \mathrm{~cm}$ below the infusion swivel. The opposite end of the silica tubing was attached to the PE tubing near the liquid swivel with a masking tape in order to attach the sample collection vials. The probe was secured in place by stainless steel collars that were screwed onto the guide cannula. The external length of the PE tubing was protected from chewing by a steel spring casing. The probes were inserted the day before the beginning of microdialysis testing. To prevent occlusion, artificial CSF $\left(145 \mathrm{mM} \mathrm{Na}^{+}\right.$, $2.7 \mathrm{mM} \mathrm{K}^{+}, 1.2 \mathrm{mM} \mathrm{Ca}^{2+}, 1.0 \mathrm{mM} \mathrm{Mg}^{2+}, 150 \mathrm{mM} \mathrm{Cl}^{-}$, $0.2 \mathrm{mM}$ ascorbate, $2 \mathrm{mM} \mathrm{Na}_{2} \mathrm{HPO}_{4}, \mathrm{pH} 7.4+0.1$ ) was perfused overnight at a rate of $0.03 \mu \mathrm{l} / \mathrm{min}$.

High-performance liquid chromatography. A $10 \mu \mathrm{l}$ volume of dialysate was extracted from each sample and analyzed immediately using one of two similar HPLC systems with electrochemical detection (HPLC-EC). The samples were loaded onto C-18 reverse-phase columns $(5 \mu \mathrm{m}, 15 \mathrm{~cm})$ through manual injection ports (Reodyn 7125; $20 \mu$ loop); reduction and oxidation currents for DA and its metabolites (dihydroxyphenylacetic acid (DOPAC), homovanillic acid (HVA), and 5-hydroxyindole acetic acid (HIAA)) were measured with dual-channel ESA coulometric detectors (Coulochem III, with a model 5011 analytical cell). The currents for DA were measured independently of those for DOPAC, HVA, and HIAA using separate channels of the Coulochem detectors. The mobile phases $(20 \%$ acetonitrile, $0.076 \mathrm{M}$ SDS, $0.1 \mathrm{M}$ EDTA, $0.058 \mathrm{M} \mathrm{NaPO}_{4}, 0.27 \mathrm{M}$ citric acid, $\mathrm{pH}$ 3.35) were circulated through each closed system at a flow rate of $1.1 \mathrm{ml} / \mathrm{min}$ by Waters 515 HPLC pumps. The peaks obtained for DA, DOPAC, HVA, and HIAA were integrated and quantified by the EZChrom Chromatography Data System (Scientific Software Inc., San Ramon, CA). The mobile phase was adjusted to allow for the separation and quantification of DA, DOPAC, HVA, and HIAA in a single run.

\section{Self-Administration}

A total of 18 Plexiglas custom-made operant boxes (Concordia University, Montreal, QC) were used for this experiment and each was enclosed in a sound-attenuating plywood chamber. Each operant box had four levers (Med Associates, Lafayette, IN) located $10 \mathrm{~cm}$ above the floor of the box: two retractable ('active') and two stationary ('inactive'). One of each type was located on opposite walls of the chamber, $10 \mathrm{~cm}$ apart from each other. The retractable levers were connected to an infusion pump for the delivery of drugs (Razel Scientific Instruments, Stamford, CT) positioned outside the sound-insulating chamber. The stationary levers served to control for baseline, nonreinforced, operant behavior; depression of this lever had no consequences, but all presses were recorded. There were two white light stimuli (one constant light and one flashing) $3 \mathrm{~cm}$ above each active lever that came on for $30 \mathrm{~s}$ at the beginning of the session, and for the duration of each drug infusion, thus serving as a discrete conditioned stimuli (CS) for drug delivery. Throughout the experiment, each selfadministration session was started by the illumination of a red house light that remained on for the duration of the 
session. Each self-administration chamber was fitted to deliver constant-current, intermittent, inescapable, electric footshock through a scrambler to the grid floor (Med Associates, Lafayette, IN).

\section{Drugs}

Heroin (diacetylmorphine $\mathrm{HCl}$ ) was purchased from Almat Pharmachem Inc. (Concord, $\mathrm{ON}$ ), cocaine (cocaine $\mathrm{HCl}$ ) from Medisca Pharmaceutique (Montreal, QC), and buprenorphine $\mathrm{HCl}$ from Reckitt Benckiser Healthcare Limited (Hull, UK).

The doses used for the self-administration experiment (heroin, $0.05 \mathrm{mg} / \mathrm{kg} / \mathrm{inf}$; cocaine, $0.5 \mathrm{mg} / \mathrm{kg} / \mathrm{inf}$ ) were chosen on the basis of previous research in this laboratory showing that these doses will produce similar levels of responding under extinction conditions when animals are trained to self-administer both drugs (Leri and Stewart, 2001). Furthermore, Leri et al (2004) used these doses in a similar study to test the efficacy of methadone on spontaneous and drug- and stress-induced reinstatement of heroin and cocaine seeking allowing for comparisons between the studies of the two opioid addiction treatment drugs. The high dose of buprenorphine used in this experiment $(3.0 \mathrm{mg} / \mathrm{kg} / \mathrm{day}$; BUP3) was chosen because it is the highest dose able to be put into solution without the addition of alcohols and because high doses of buprenorphine are well tolerated (Walsh et al, 1994).

\section{PROCEDURES}

\section{Locomotor Activity}

At 1 week after arrival in the colony, 31 rats were placed in the activity chambers in order to habituate to the chambers and provide a measure of baseline locomotion that was utilized to match the experimental groups. On each day of testing, the rats were placed in the chambers in a darkened room and the photocells were activated. The computer started the 120 -min session as soon as the rats were in the chambers. For each chamber, the total number of horizontal infrared beam breaks provided the measure of horizontal locomotion. Once the groups were matched on the basis of the locomotion scores, osmotic minipumps were implanted, creating three buprenorphine treatment groups $(0 \mathrm{mg} / \mathrm{kg} /$ day (BUP0), $1.5 \mathrm{mg} / \mathrm{kg} /$ day (BUP1.5), and $3.0 \mathrm{mg} / \mathrm{kg} /$ day (BUP3)). At 3 days after surgery (day 3), rats were given saline injections and returned to the locomotor chambers (saline test) for the 120-min test. On days 7 and 10, the rats received heroin $(0.25 \mathrm{mg} / \mathrm{kg}$, s.c.) and cocaine $(20 \mathrm{mg} / \mathrm{kg}$, i.p.) injections in a counterbalanced fashion such that every rat received both drugs, but half the rats in each group received heroin first (heroin test), and the other half received cocaine (cocaine test).

\section{Microdialysis}

Different groups of rats $(n=58)$ were used for the microdialysis experiments. At 3 days before the studies were initiated, osmotic minipumps were implanted, creating three treatment groups ( $0 \mathrm{mg} / \mathrm{kg} /$ day (BUP0), $1.5 \mathrm{mg} / \mathrm{kg} /$ day (BUP1.5), and $3.0 \mathrm{mg} / \mathrm{kg} / \mathrm{day}$ (BUP3)). In the late afternoon of day 3 after minipump implantation, microdialysis probes were inserted into the guide cannula of four rats (at least one from each group) and dialysate was infused at a rate of $0.3 \mu \mathrm{l} / \mathrm{min}$ overnight. Dialysate sampling and activity monitoring began the next morning. The dialysate flow rate was increased to $0.7 \mu \mathrm{l} / \mathrm{min}$, and baseline dialysate samples (approximately $14 \mu \mathrm{l}$ ) were collected every $20 \mathrm{~min}$ and analyzed immediately. Dialysate samples from individual rats were analyzed consistently using one of the two HPLC-EC systems and the assignment of the animals to each system was counterbalanced across all treatment conditions. Once stable baseline levels of DA and its metabolites (DOPAC and HVA) were attained (less than $10 \%$ variation in three consecutive samples), the rats were injected with one of three doses of heroin $(0.125,0.25$, or $0.375 \mathrm{mg} / \mathrm{kg}$, s.c.) or cocaine $(10,20$, or $30 \mathrm{mg} / \mathrm{kg}$, i.p.) and samples were collected at 20 -min intervals for $140 \mathrm{~min}$. On the following day, the identical protocol was used and each rat received an injection of one of the doses of the other drug, such that each rat was given one dose of heroin and one of cocaine. The order of the drug administration was counterbalanced within the groups. Food was removed from the chambers before sampling, but a water-drinking tube was available throughout.

Postmortem tissue analysis. Following the two test days, the rats were perfused intracardially with saline and formaldehyde (formalin 10\% V/V, Anachemia, Montreal, QC) before having their brains removed. In order to identify the placements of the cannula tract and probes, horizontal frozen sections were taken using a cryostat, mounted, and stained with cresyl violet.

\section{Self-Administration}

An additional eighteen rats were trained to self-administer both heroin $(0.05 \mathrm{mg} / \mathrm{kg} / \mathrm{inf})$ and cocaine $(0.5 \mathrm{mg} / \mathrm{kg} / \mathrm{inf})$ in the same chambers on alternate days in a counterbalanced fashion, such that some rats had access to cocaine first and others heroin first. Each drug was paired with a distinct lever and light pattern as outlined above such that one 'active' and one 'inactive' lever were in use each day. Half of the rats had heroin paired with the right lever (constant light) and cocaine paired with the left lever (flashing light).

Training. Rats were given access to drugs for a total of 16 3-h self-administration sessions, eight sessions with each drug on alternate days. The sessions were conducted once per day with two groups of rats commencing their sessions at 0800 and $1100 \mathrm{~h}$, respectively. Each rat had access to a specific chamber and had access at the same time each day. For each self-administration session, the rats were transported from the colony to the experimental room and placed in the operant chambers. Each rat had its protective cap and blocker removed and was connected to the drug infusion tubing with a protective spring sleeve screwed to the cannula mounted on the skull. This functioned to protect the tubing from the rat and to secure the tubing to the cannula. Once the rats were secured in their respective chambers, there was a 5-min time-out period that allowed the rats to acclimate to the chambers. 
Following the 5-min period, the red house light was turned on and remained on for the duration of the session. After $10 \mathrm{~s}$, the retractable lever was extended and the cue light was activated for $30 \mathrm{~s}$. This light remained on for $30 \mathrm{~s}$ unless a response was made; if there was a response, it stayed on for the duration of the 10-s drug infusion. A fixed ratio 1 (FR1) schedule of reinforcement was used such that the first active lever press resulted in a 10-s drug infusion (approximately $64 \mu \mathrm{l}$ ). During the infusion, presses on the active lever had no additional consequence, but were recorded, as were presses on the inactive lever. Following the 180 -min session, the active lever was retracted and the house light was extinguished.

Surgery. Following the last self-administration day (day 16), all rats were prepared for surgery as outlined above. The rats in the buprenorphine (BUP3) experimental group had pumps implanted s.c., and those in the control group (BUP0) had sham surgery performed but no pump implanted. After surgery, rats were returned to their home cages and allowed $24 \mathrm{~h}$ to recover. This was thought to be enough time to recover and allowed an evaluation of the immediate effects of the chronic buprenorphine treatment on spontaneous heroin and cocaine seeking during extinction.

Extinction. The next day, rats were brought back to the selfadministration boxes and connected as before. On the first day of extinction, the procedure was identical to that used in the self-administration sessions, with the exception that both the heroin and cocaine levers were present and no drugs were available during the 3 -h session. During the 6 days of extinction, a depression of either of the two retractable levers resulted in the appropriate cue light and the activation of the pump for $10 \mathrm{~s}$. In each case, an empty syringe was connected to the tubing to seal the system, but was not placed in the syringe pump.

Drug-induced reinstatement. On the seventh day, rats were placed into the self-administration boxes for another extinction session lasting only $1 \mathrm{~h}$. If the extinction criterion was met in the first hour (less than 15 active lever presses), the session was terminated and the first reinstatement session was initiated. When more than 15 responses were made on either active lever, another 1-h extinction session was started $15 \mathrm{~min}$ following the termination of the previous session until extinction criterion was achieved for each rat. For the drug-induced reinstatement, half of the rats received an injection of heroin $(0.25 \mathrm{mg} / \mathrm{kg}$, s.c. $)$, and the other half received an injection of cocaine $(20 \mathrm{mg} / \mathrm{kg}$, i.p.) $15 \mathrm{~min}$ before returning to the self-administration boxes. These doses were chosen on the basis of previous work in this laboratory, demonstrating that these doses are effective at reinstating heroin and cocaine seeking to similar levels in rats trained to self-administer both drugs (Leri and Stewart, 2001; Leri et al, 2004). Once the rats were returned to the chambers, following a 15-min timeout period, the session began as each previous extinction session with the house light illuminated for $10 \mathrm{~s}$ before the extension of the two retractable levers and the activation of both cue lights for $30 \mathrm{~s}$. As in previous sessions, the number of active responses on both levers was recorded as well as the number of inactive lever responses. Following the reinstatement session, rats were returned to their home cages.

The next day, the rats were given a 3-h extinction session to extinguish any residual responding before the next reinstatement session. On the next day, rats were given another $1-\mathrm{h}$ extinction session to determine whether the extinction criterion had been met. If so, the next reinstatement session was started and, if not, another 1-h extinction session was given until the criterion was met. On the second reinstatement session, the rats received the drug that they had not received on the first reinstatement session.

Footshock stress-induced reinstatement. On the day after the last drug test, rats were returned to the self-administration boxes for a 3-h extinction session. The final day of testing began with a 1-h extinction session to determine whether the extinction criterion had been met. Once this was attained, the rats were exposed to $15 \mathrm{~min}$ of intermittent, inescapable, footshock stress in the self-administration boxes $(0.8 \mathrm{~mA}, 0.5 \mathrm{~s} / \mathrm{shock}, 40 \mathrm{~s}$ mean OFF time). A pilot study showed these to be the optimal intensity and duration of exposure to footshock stress for reinstatement in rats trained to self-administer cocaine; in addition, these parameters had been used in previous studies in this laboratory (Leri et al, 2002, 2004). Following the shock exposure, the 3-h session began with the illumination of the red house light for $10 \mathrm{~s}$ prior to extension of the two retractable levers and the activation of the cue lights for $30 \mathrm{~s}$.

Statistical analyses. Data from each of the experiments were analyzed using ANOVAs for treatment groups by time, as appropriate. Post hoc comparisons between means were made using Fisher's LSD test $(p<0.05)$.

\section{RESULTS}

\section{Locomotor Activity}

Figure 1 shows the mean total activity levels of the three buprenorphine treatment groups on each of the test days. An ANOVA conducted on the 2-h activity scores revealed a significant main effect of group $(\mathrm{F}(2,28)=3.41, p<0.05)$ and test $(\mathrm{F}(4,112)=80.78, p<0.0001)$ and a group by test interaction $(\mathrm{F}(8,112)=4.22, p<0.0001)$. This group by test interaction reflects the fact that rats treated with buprenorphine, BUP1.5, and BUP3 had higher scores than the BUP0 only on the saline and cocaine tests; the response to heroin was unaffected by buprenorphine. We next examined the locomotor activity in 20-min intervals across the 2-h session and noted that the differences between groups remained stable across time (data not shown). Separate ANOVAs were carried out for each of the three tests, and in each case the group by time interactions were not significant (saline: $\mathrm{F}(10,140)=1.542, \quad p=0.131$; heroin: $\mathrm{F}(10,140)=0.374$, $p=0.956$; cocaine: $\mathrm{F}(10,140)=0.814, p=0.615)$.

It can also be noted that, in the initial test given before pump implantation, there was no significant main effect of group $(\mathrm{F}(2,28)=0.15, p=0.86)$, showing that the groups were matched for their basal activity scores. The effect of chronic buprenorphine on activity can be seen on the saline test given after implantation of the pumps. Though not 


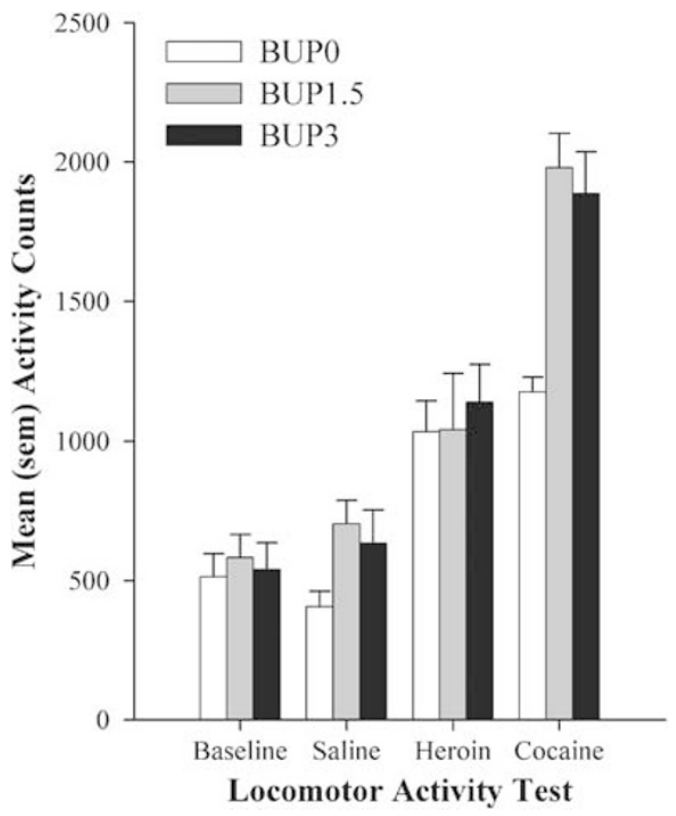

Figure I Mean (SEM) locomotor activity counts in buprenorphine treatment groups (BUPO, $n=10$; BUPI.5, $n=10 ; B \cup P 3, n=11$ ) before implantation of minipumps (baseline), and in response to saline (day 4), heroin $(0.25 \mathrm{mg} / \mathrm{kg}$, s.c., day $7-10)$, and cocaine $(20 \mathrm{mg} / \mathrm{kg}$, i.p., day $7-10)$ injections during buprenorphine maintenance.

significant, there was a tendency for the buprenorphine groups to be more active $(\mathrm{F}(2,28)=2.77, p=0.08)$ (Figure 1).

\section{Microdialysis}

The effect of acute administration of heroin on extracellular levels of DA in the NAc in buprenorphine-maintained rats is shown in Figure 2. It can be seen that the response to all doses of heroin was suppressed in buprenorphine-maintained rats. An ANOVA comparing the groups at each dose of heroin revealed significant main effects of group $(\mathrm{F}(2,41)=6.607, p<0.01)$, heroin dose $(\mathrm{F}(2,41)=5.940$, $p<0.01)$, and time $(\mathrm{F}(5,205)=7.191, p<0.0001)$, and a heroin dose by time interaction $(\mathrm{F}(10,205)=2.186$, $p<0.05)$. Separate ANOVAs were carried out on the postinjection samples (20-120 min) for each dose of heroin. At the lowest dose of heroin $(0.125 \mathrm{mg} / \mathrm{kg}$, s.c.), there was no significant effect of buprenorphine treatment (Figure 2a). At the intermediate dose of heroin $(0.250 \mathrm{mg} / \mathrm{kg}$, s.c. $)$, however, buprenorphine treatment suppressed the levels of DA (see Figure 2b). The ANOVA carried out on the postinjection samples revealed significant effects of group $(\mathrm{F}(2,13)=6.125, \quad p<0.05)$ and time $(\mathrm{F}(5,65)=3.840$, $p<0.005)$. Post hoc comparisons indicated that the BUP0 group differed significantly from both the BUP1.5 and BUP3 groups. Similar effects were seen at the highest dose of heroin $(0.375 \mathrm{mg} / \mathrm{kg}$, s.c. $)$; the ANOVA revealed significant group $(\mathrm{F}(2,15)=3.583, p=0.05)$ and time $(\mathrm{F}(5,75)=4.952$, $p<0.001)$ effects. Once again the post hoc comparisons showed that the BUP0 group had significantly higher levels of DA than either the BUP1.5 or the BUP3 buprenorphine treatment groups (see Figure 2c).
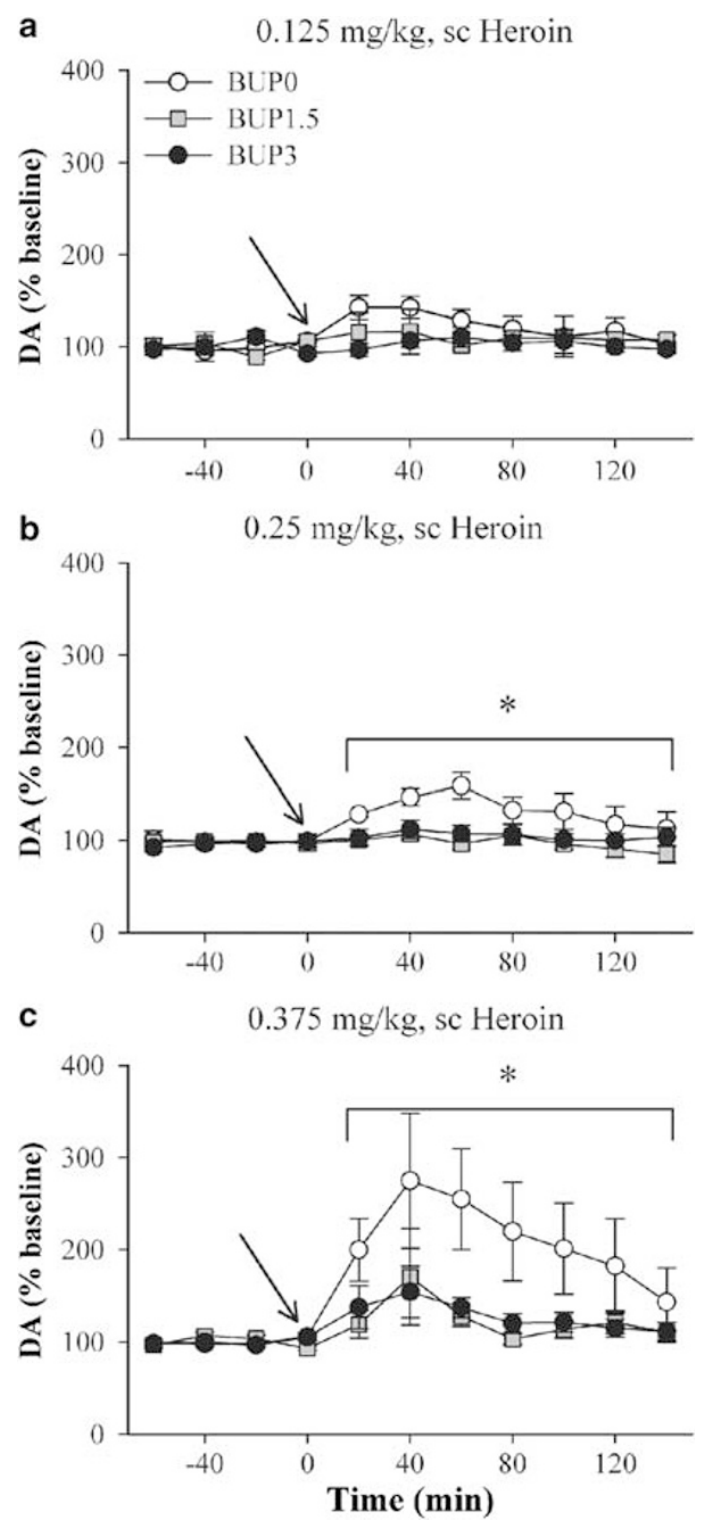

Figure 2 Mean percent increase in extracellular DA in the nucleus accumbens in response to acute injections of heroin (day 4 or 5 ) in the buprenorphine treatment groups (BUPO, BUPI.5, and BUP3). (a) $0.125 \mathrm{mg} /$ $\mathrm{kg}$, s.c., heroin, $n=6$ per group. (b) $0.25 \mathrm{mg} / \mathrm{kg}$, s.c., heroin (BUPO, $n=4$; BUPI.5, $n=6 ;$ BUP3, $n=6$ ). (c) $0.375 \mathrm{mg} / \mathrm{kg}$, s.c., heroin (BUPO, $n=5$; BUPI.5, $n=7$; BUP3, $n=6$ ). * Significant group effects following heroin injection, $p<0.05$. Arrow indicates when the injection was given. All groups received only one dose of heroin and one of cocaine in a counterbalanced order.

The effects of buprenorphine treatment on the effects of acute cocaine injections are illustrated in Figure 3. It can be seen that the extracellular DA response in the NAc to cocaine was potentiated in buprenorphine-maintained rats. An overall ANOVA was carried out to examine the effects of each dose of cocaine in each of the buprenorphinetreated groups. This ANOVA revealed significant group $(\mathrm{F}(2,44)=5.532, \quad p<0.01)$ and cocaine dose $(\mathrm{F}(2,44)=11.296, p<0.001)$ effects, and group by cocaine dose $(\mathrm{F}(4,44)=2.874, p<0.05)$ and group by cocaine dose by time $(F(20,220)=1.606, p<0.05)$ interactions. Separate ANOVAs were then carried out on the data from each dose 
a

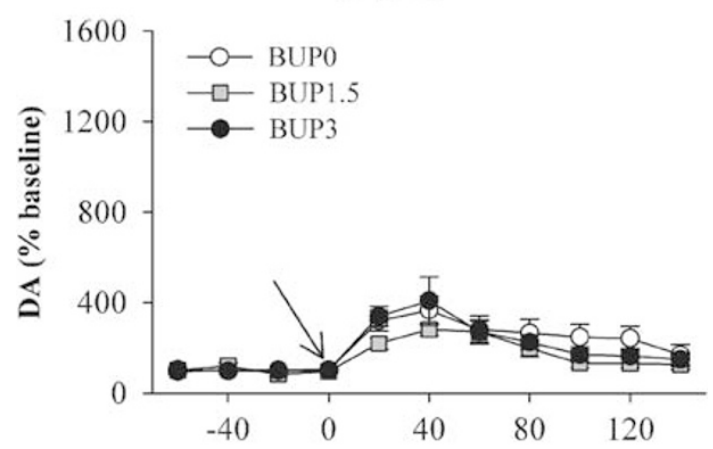

b

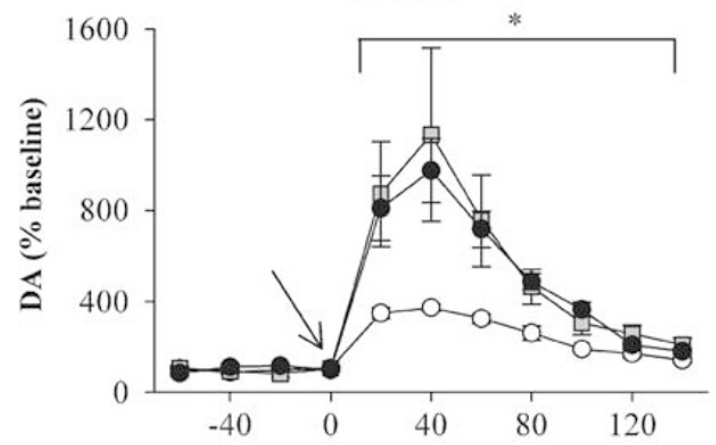

C

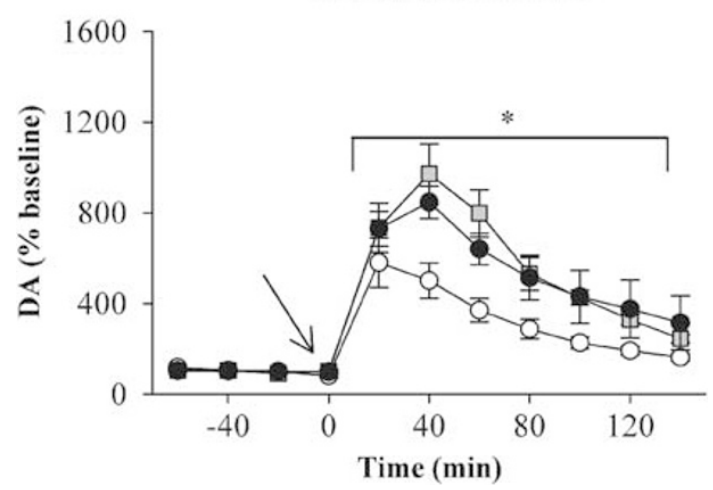

Figure 3 Mean percent increase in extracellular DA in the nucleus accumbens in response to acute injections of cocaine (day 4 or 5 ) in the buprenorphine treatment groups (BUPO, BUPI.5, and BUP3). (a) $10 \mathrm{mg} / \mathrm{kg}$, i.p., cocaine (BUPO, $n=4$; BUPI.5, $n=6$; BUP3, $n=7$ ). (b) $20 \mathrm{mg} / \mathrm{kg}$, i.p., cocaine (BUPO, $n=6$; BUPI.5, $n=7$; BUP3, $n=7$ ). (c) $30 \mathrm{mg} / \mathrm{kg}$, i.p., cocaine (BUPO, $n=5 ; \mathrm{BUPI} .5, n=7 ; \mathrm{BUP} 3, n=6$ ). *Significant group effects following cocaine injection, $p<0.05$. Arrow indicates when the injection was given. All groups received only one dose of heroin and one of cocaine in a counterbalanced order.

of cocaine. No group differences were found at the lowest dose of cocaine $(10 \mathrm{mg} / \mathrm{kg}$, i.p.), though there was a significant effect of time $(\mathrm{F}(5,65)=8.652, p<0.001)$ (Figure 3a). At the intermediate dose of cocaine $(20 \mathrm{mg} /$ $\mathrm{kg}$, i.p.), buprenorphine enhanced DA overflow; there were significant effects of group $(\mathrm{F}(2,14)=4.739, p<0.05)$ and time $(5,70)=20.175, p<0.001)$ and a time by group interaction $(\mathrm{F}(10,70)=2.964, p<0.01)$. Post hoc analyses showed that the BUP0 group had significantly lower scores than both the BUP1.5 and BUP3 buprenorphine treatment groups (see Figure $3 b$ ). Similar effects were seen at the highest dose of cocaine $(30 \mathrm{mg} / \mathrm{kg}$, i.p.); as shown in Figure 3c, buprenorphine augmented the effects of cocaine on NAc DA. The ANOVA revealed a significant effect of time $(\mathrm{F}(5,85)=2.731, p<0.001)$, group effect $(p=0.07)$; the BUP0 group differed significantly from both the BUP3 and BUP1.5 groups.

Inspection of microdialysis probe placements in animals in all of the groups revealed considerable variability resulting in variations in basal NAc DA levels. In order to determine whether buprenorphine affected basal levels of DA, we examined the actual levels in each of the treatment groups comparing only those animals with nearly identical placements within the NAc core and shell at three points anterior to Bregma $(+1.2,1.6$, and $1.7 \mathrm{~mm})$. Some animals were eliminated from the analysis at each distance from Bregma due to the fact that the placement of the probe was either lateral, medial, or dorsal from the majority. It can be seen from Figure 4 that at each distance from Bregma there was a clear tendency for BUP1.5 and BUP3 groups to have higher levels of DA than BUP0 over the four samples. The ANOVA carried out on the data from each time point at each distance from Bregma revealed only a trend towards a group effect $(\mathrm{F}(2,36)=17.744$, $p=0.11)$.

Taken together, irrespective of location from Bregma, there were no significant main effects, though there was a trend towards a group effect. Though unwarranted, post hoc comparisons revealed that, across each location, basal NAc DA levels in BUP3 rats were significantly higher than BUP0 rats $(p<0.05)$ (see Figure 4$)$. Microdialysis probe placements for all rats are shown in Figure 5.

\section{Self-Administration}

Training. Rats developed reliable heroin and cocaine selfadministration during the eight training sessions with each drug. On the final three days of heroin self-administration, the mean number of responses on the two levers (active \pm sem $v s$ inactive \pm SEM) were $32.00 \pm 20.11$ vs $0.72 \pm 0.29,17.39 \pm 5.66$ vs $0.78 \pm 0.26$, and $13.94 \pm 2.26$ vs $1.06 \pm 0.34$. The number of responses on the cocaine levers (active \pm SEM $v s$ inactive \pm SEM) on the last three days of training were: $47.28 \pm 15.28$ vs $3.50 \pm 1.67,57.78 \pm 20.05$ vs $4.17 \pm 1.67$, and $31.50 \pm 4.746$ vs $3.17 \pm 1.40$. These results show clearly that rats responded preferentially on the drugassociated levers. Rats were subsequently assigned to treatment groups matched on the basis of scores during training, at which time pumps were implanted into the BUP3 group only $(n=10)$, while the remaining eight rats received sham surgery (BUP0 group). The animals were returned to their home cages following surgery and extinction training began the next day.

Extinction. Buprenorphine treatment reduced drug seeking during extinction in these rats previously trained to selfadminister both heroin and cocaine. It can be seen in Figure 6 that, when both the heroin- and cocaine-associated levers were present, responding on both levers was reduced over the first three extinction sessions in the BUP3 group compared to that in the BUP0 group. An ANOVA on data from the heroin-associated lever (Figure 6a) revealed significant effects of group $(\mathrm{F}(1,16)=11.11, p<0.005)$ and 
a

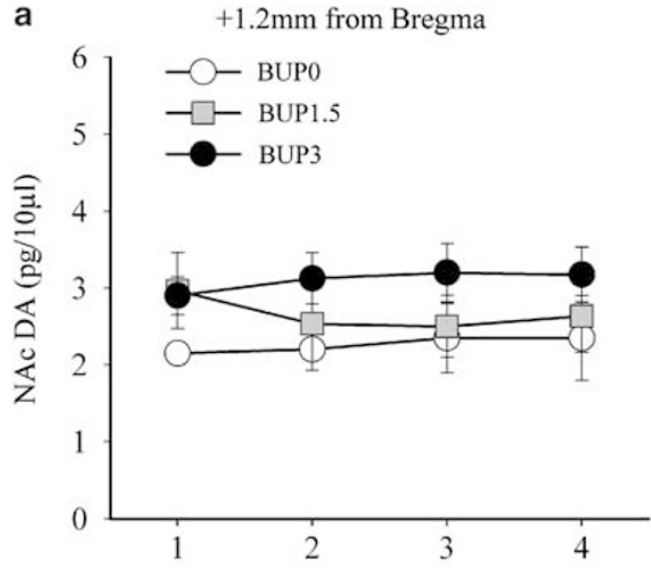

b

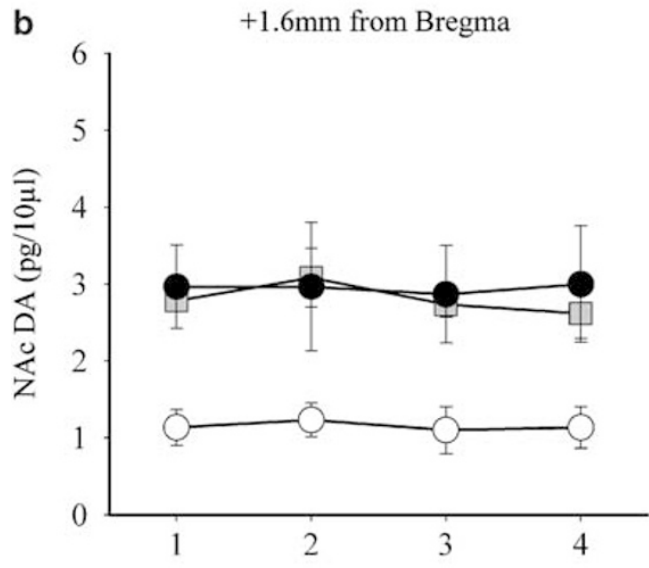

c

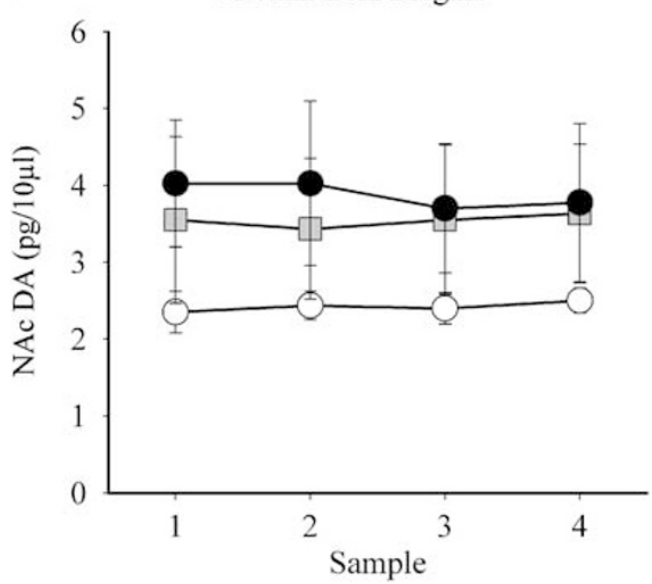

Figure 4 Mean $(S E M)$ basal DA level $(p g / \mid 0 \mu l)$ in four consecutive 20 -min samples during in vivo microdialysis at (a) $+1.2 \mathrm{~mm}$ from Bregma (BUPO, $n=2$; BUPI.5, $n=3$; BUP3, $n=4$ ), (b) $+1.6 \mathrm{~mm}$ from Bregma (BUPO, $n=3$; BUPI.5, $n=6$; BUP3, $n=3$ ), and (c) $+1.7 \mathrm{~mm}$ from Bregma (BUPO, $n=8 ;$ BUPI.5, $n=6 ;$ BUP3, $n=4$ ) for each buprenorphine treatment group.

time $(\mathrm{F}(5,80)=28.30, p<0.001)$, and a significant group by time interaction $(\mathrm{F}(5,80)=5.90, p<0.001)$. Similarly, in the case of the cocaine-associated lever (Figure 6b), buprenorphine reduced responding; the ANOVA revealed significant effects of group $(\mathrm{F}(1,16)=11.18, p<0.005)$ and time $(\mathrm{F}(5,80)=29.60, p<0.001)$, and a significant group by time interaction $(\mathrm{F}(5,80)=9.79, p<0.001)$.

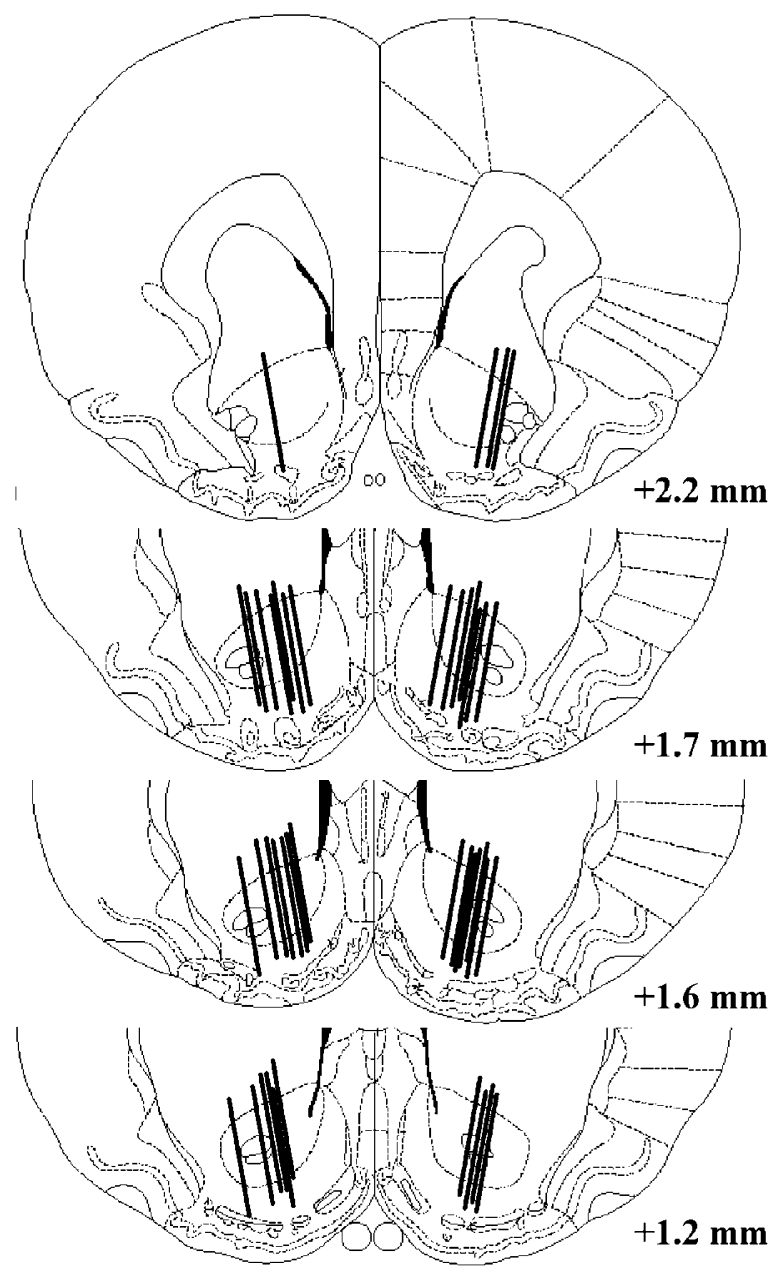

Figure 5 Microdialysis probe placements for all rats. Black lines indicate the probable probe sampling area verified following histological preparation.

Reinstatement. Three tests for reinstatement were conducted following the extinction sessions: a heroin, a cocaine, and a footshock test. During these tests, both the heroin and cocaine levers were present, but pressing led only to the onset of the drug-associated cues. An overall ANOVA for group $\times$ test was carried out on the data from both drug-associated levers. In both the heroin and cocaine tests for reinstatement (in the BUP0 group), responding was lever selective as previously reported in such test (Leri and Stewart, 2001; Leri et al, 2004); rats responded more on the heroin-associated lever after a heroin injection and more on the cocaine-associated lever after an injection of cocaine; in the test for footshockinduced reinstatement, responding on the two levers did not differ. The ANOVA revealed significant group $\times$ test $(\mathrm{F}(2,32)=4.083, p<0.05), \quad$ lever $\times$ test $\quad(\mathrm{F}(2,32)=36.744$, $p<0.001)$ and group $\times$ lever $\times$ test $\quad(\mathrm{F}(2,32)=24.328$, $p<0.001)$ interactions. As shown in Figure $7 \mathrm{a}$ and $\mathrm{b}$, and supported by post hoc analysis, buprenorphine suppressed responding after both heroin and cocaine priming injections on the lever associated with the priming drug. There was no effect of buprenorphine on the test with footshock stress. 

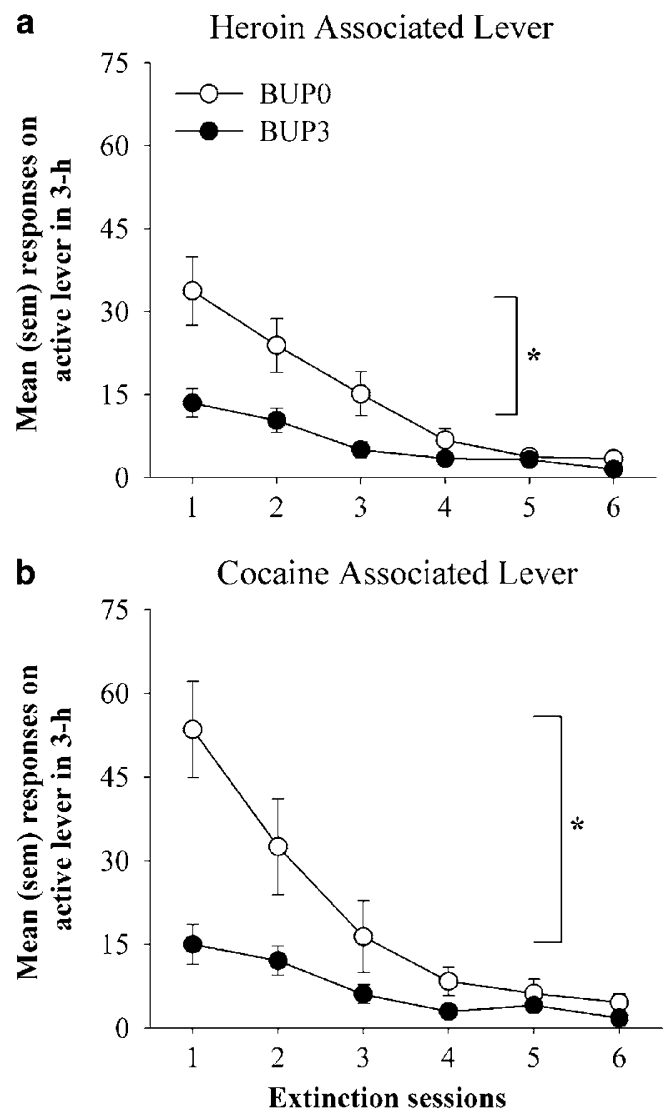

Figure 6 Total responses during extinction in each 3-h daily session. (a) Mean (SEM) responses made on the active lever previously associated with heroin by the BUPO and BUP3 groups. (b) Mean (SEM) responses made on the active lever previously associated with cocaine by the BUPO and BUP3 groups. During extinction sessions all cues previously associated with drug availability and infusions were present. *Significant group effect, $p<0.005$.

\section{DISCUSSION}

The primary findings of this study are that chronic maintenance on buprenorphine significantly reduces drug seeking during extinction in the presence of drug-associated cues and reduces reinstatement of drug seeking in response to both heroin and cocaine, but has no effect on reinstatement induced by footshock stress. Interestingly, these findings parallel those recently reported from this laboratory on the effects of methadone maintenance via minipump (Leri et al, 2004) and suggest that maintenance on buprenorphine has the potential to reduce both heroin and cocaine seeking. These data cannot be explained by a suppression of general activity by buprenorphine; in fact, rats maintained on buprenorphine had slightly higher basal levels of activity than rats without buprenorphine. In this regard, it is interesting that the buprenorphine-maintained rats also had higher basal levels of DA in the NAc, suggesting that chronic low-level activation of DAergic function might play a role in suppression of drug seeking, but in our view this, in itself, seems an unlikely explanation. However, because of these findings on the effects of buprenorphine on basal levels of DA in the NAc and because the effects of buprenorphine paralleled so closely a Heroin Associated Lever
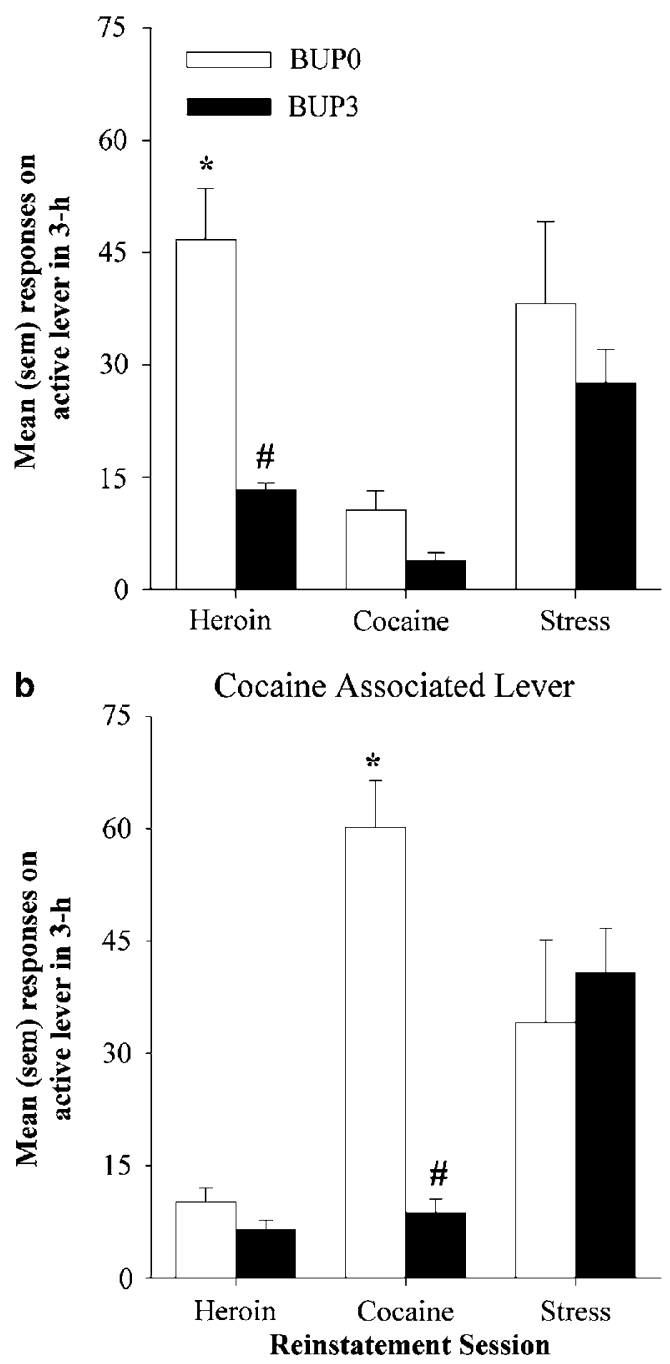

Figure 7 Total responses on the active levers during 3-h tests for reinstatement. (a) Mean (SEM) responses made on the active lever previously associated with heroin by the BUPO and BUP3 groups following heroin $(0.25 \mathrm{mg} / \mathrm{kg}$ s.c.), cocaine $(20 \mathrm{mg} / \mathrm{kg}$, i.p.), and $15 \mathrm{~min}$ of intermittent footshock stress ( $0.8 \mathrm{~mA}, 0.5 \mathrm{~s} / \mathrm{shock}, 40 \mathrm{~s}$ mean OFF time). (b) Mean (SEM) responses made on the active lever previously associated with cocaine by the BUPO and BUP3 groups in each of the 180-min reinstatement sessions following heroin, cocaine, and footshock stress. Responding was lever selective following heroin and cocaine priming: \# significant difference between the number of responses on the heroinand cocaine-associated levers, $p<0.001$. Buprenorphine suppressed druginduced responding selectively: *Significant group effect, $p<0.05$.

the effects seen previously with methadone in our studies (Leri et al, 2004), we carried out a subsequent study on the effects of methadone delivered by osmotic minipump on basal levels of DA. Interestingly, the effect of methadone was similar to that of buprenorphine; 30.0 and $40.0 \mathrm{mg} / \mathrm{kg} /$ day methadone yielded mean basal levels of 7.5 and $7.6 \mathrm{pg} /$ $10 \mu \mathrm{l}$, respectively, compared to $4.5 \mathrm{pg} / 10 \mu \mathrm{l}$ for the control group. (Note that the overall levels of basal DA in this experiment were higher than in the buprenorphine study, probably as a result of more dorsal placements of the dialysis probes.) 
Even if the higher basal levels of DA in the NAc were contributing to the reduced effectiveness of drug-related cues in extinction conditions, it is not easy to relate the findings on suppression of drug-induced reinstatement by buprenorphine to the effects of buprenorphine on the acute DAergic response to heroin and cocaine. Buprenorphine attenuated the extracellular levels of DA in the NAc in response to heroin, but potentiated the DA response to cocaine. Furthermore, chronic buprenorphine had no effect on heroin-induced locomotor activity, but significantly elevated cocaine-induced activity, as previously reported with acute buprenorphine (Smith et al, 2003). It can be noted that significant differences were never found between the doses of buprenorphine used. This may be due to the finding of Greenwald et al (2003) that a dose of $16 \mathrm{mg}$ results in $80 \pm 2 \% \mathrm{mu}$ opioid receptor occupancy, whereas twice this dose $(32 \mathrm{mg}$ ) results in only $84 \pm 2 \%$ occupation.

Buprenorphine is a partial $m u$ opioid agonist with antagonistic properties at the kappa and delta opioid receptors. It is characterized primarily by its actions at the $m u$ receptor and its therapeutic effects are attributed to its high affinity and slow dissociation (Tzschentke, 2002). Buprenorphine, like morphine, is thought to exert its effects in the brain by activation of $m u$ opioid receptors located on GABA interneurons in the ventral tegmental area (VTA) (Devine et al, 1993; Garzon and Pickel, 2001). Chronic administration of buprenorphine would maintain continuous activation of opioid receptors, thus causing chronic elevation of DA levels within the mesolimbic system (see Figure 4), unless tolerance were developing. The finding that chronic buprenorphine maintenance $(3.0 \mathrm{mg} / \mathrm{kg} / \mathrm{day})$ reduced heroin-induced reinstatement of drug responding is consistent with the findings from microdialysis and what could be predicted from the pharmacokinetics of the two drugs. The high affinity for, and the slow dissociation from, the $m u$ opioid receptor would make buprenorphine somewhat of a 'sticky' drug that would not be readily displaced by heroin. However, buprenorphine (BUP1.5 and BUP3) did not block the stimulatory effect of the acute injection of heroin, and only attenuated the accompanying rise in extracellular DA in the NAc, suggesting that tolerance had not developed.

Despite the fact that buprenorphine reduced cocaineinduced reinstatement, there was a clear potentiation of the locomotor effect of an acute injection of cocaine. Additionally, a significant increase in extracellular DA levels following cocaine was observed in the buprenorphinetreated rats. This effect was not surprising; synergistic effects between opiates and stimulants have been found in many situations including place conditioning (Brown et al, 1991), locomotion (Smith et al, 2003), conditioned reward (Cunningham and Kelley, 1992a,b), rotational behavior in rats with lesions of the substantia nigra (Kimmel et al, 1997), and drug toxicity (Plunkett et al, 1989). Therefore, it remains somewhat puzzling that buprenorphine $(3.0 \mathrm{mg} / \mathrm{kg} /$ day) reduced cocaine-induced reinstatement of drug seeking over the full $3-\mathrm{h}$ session, while potentiating the rise in extracellular DA levels and the accompanying rise in locomotion. One explanation might have been that the combination of buprenorphine and cocaine and the accompanying high levels of DA were experienced as a very high dose of cocaine, making it likely that responding (cocaine seeking) would be low initially, but persist as the effects of the drug diminished. The fact that this is not what was observed suggests that the effect of buprenorphine was to reduce drug seeking directly and, as in the case of extinction, the salience or effectiveness of the drug-related cues.

Although buprenorphine treatment $(3.0 \mathrm{mg} / \mathrm{kg} /$ day $)$ was effective at reducing spontaneous and drug-induced reinstatement of responding for both heroin and cocaine, it was ineffective at reducing responding following footshock stress. This finding is consistent with previous research from this lab demonstrating that neither heroin (Shaham et al, 1996) nor methadone (Leri et al, 2004) maintenance, nor other opiate antagonists (Shaham and Stewart, 1996), are effective at reducing footshock stress-induced reinstatement. Once again, this is evidence for a dissociation between the systems underlying drug- and stress-induced responding (for reviews, see Stewart, 2000, 2003). As mentioned previously, the constellation of findings seen here in rats given buprenorphine chronically via osmotic minipumps resembles closely that found in similar experiments from this laboratory in rats treated chronically with methadone (Leri et al, 2004). Methadone significantly reduced extinction responding in rats trained to selfadminister both heroin and cocaine, and reduced reinstatement of lever-pressing after priming injections of heroin and cocaine selectively on the heroin- and cocaineassociated levers, without affecting reinstatement induced by footshock stress. Furthermore, these effects were found in spite of the fact that methadone slightly enhanced spontaneous locomotor activity and did not suppress the effects of cocaine on locomotion. Taken together, these findings suggest that chronic treatment with relatively high doses of drugs such as buprenorphine and methadone, both of which have been found to have beneficial effects in the treatment of opioid addiction, have the capacity to suppress the effectiveness of drug-related cues (as in extinction conditions) and to reduce drug seeking induced by both opioid and stimulant drugs.

Finally, although it has been shown that both buprenorphine and methadone are effective in reducing spontaneous and drug-induced reinstatement of heroin and cocaine seeking, we have yet to determine the mechanisms whereby they act. To date, we have searched for a relation between their effects on drug seeking and their effects on DAergic activity. Both drugs enhance basal levels of DA within the NAc, do not suppress cocaine induced locomotor activity, and, in the case of buprenorphine at least, enhance the DAergic response to cocaine. Thus, it seems clear that in the presence of buprenorphine enhanced dopaminergic activity in the NAc is not sufficient to induce drug seeking. Recent studies suggest that the actions of glutamate in the NAc are critical for the induction of cocaine seeking by priming injections of cocaine in otherwise drug-free rats. Furthermore, there is evidence that it is a projection from the medial prefrontal cortex that is involved (Capriles et al, 2003; Kalivas, 2004; McFarland et al, 2003). Interestingly, in this context, it has been shown in slices taken from rats chronically treated with morphine that NMDA activity and, possibly, glutamate release in the NAc core are significantly decreased (Martin et al, 1999; Martin et al, 1999). Thus, it may prove interesting to study the effects of buprenorphine 
on the activity of these prefrontal glutamate projections and on levels of glutamate in the NAc.

\section{ACKNOWLEDGEMENTS}

This research was supported by an Interdisciplinary Health Research Team (IHRT) grant from the Canadian Institutes of Health Research (CIHR), and operating grants from CIHR and Fond pour la Formation de Chercheurs et l'Aide à la Recherche du Québec (FCAR) to JS. RES was supported by a graduate fellowship from the Natural Science and Engineering Council of Canada (NSERC).

\section{REFERENCES}

Brown EE, Finlay JM, Wong JT, Damsma G, Fibiger HC (1991). Behavioral and neurochemical interactions between cocaine and buprenorphine: implications for the pharmacotherapy of cocaine abuse. J Pharmacol Exp Ther 256: 119-126.

Capriles N, Rodaros D, Sorge RE, Stewart J (2003). A role for the prefrontal cortex in stress- and cocaine-induced reinstatement of cocaine-seeking in rats. Psychopharmacology 168: 66-74.

Cunningham ST, Kelley AE (1992a). Evidence for opiate-dopamine cross-sensitization in the nucleus accumbens: studies of conditioned reward. Brain Res Bull 29: 675-680.

Cunningham ST, Kelley AE (1992b). Opiate infusion into nucleus accumbens: contrasting effects on motor activity and responding for conditioned reward. Brain Res 588: 104-114.

Devine DP, Leone P, Wise RA (1993). Mesolimbic dopamine neurotransmission is increased by administration of mu-opioid receptor antagonists. Eur J Pharmacol 243: 55-64.

Di Chiara G, Imperato A (1988). Drugs abused by humans preferentially increase synaptic dopamine concentrations in the mesolimbic system of freely moving rats. Proc NY Acad Sci 85: 5274-5278.

Foltin RW, Fischman MW (1996). Effects of methadone or buprenorphine maintenance on the subjective and reinforcing effects of intravenous cocaine in humans. J Pharmacol Exp Ther 278: 1153-1164.

Garzon M, Pickel VM (2001). Plasmalemmal mu-opioid receptor distribution mainly in nondopaminergic neurons in the rat ventral tegmental area. Synapse 41: 311-328.

Gonzalez G, Oliveto A, Kosten TR (2004). Combating opiate dependence: a comparison among the available pharmacological options. Curr Opin Pharmacother 5: 713-725.

Greenwald MK, Johanson CE, Moody DE, Woods JH, Kilbourn MR, Koeppe RA et al (2003). Effects of buprenorphine maintenance dose on mu-opioid receptor availability, plasma concentrations, and antagonist blockade in heroin-dependent volunteers. Neuropsychopharmacology 28: 2000-2009.

Greenwald MK, Schuh KJ, Hopper JA, Schuster CR, Johanson CE (2002). Effects of buprenorphine sublingual tablet maintenance on opioid drug-seeking behavior by humans. Psychopharmacology 160: 344-352.

Guichard A, Lert F, Calderon C, Gaigi H, Maguet O, Soletti J et al (2003). Illicit drug use and injection practices among drug users on methadone and buprenorphine maintenance treatment in France. Addiction 98: 1585-1597.

Gysling K, Wang RY (1983). Morphine-induced activation of A10 dopamine neurons in the rat. Brain Res 277: 119-127.

Johnson RE, Jaffe JH, Fudala PJ (1992). A controlled trial of buprenorphine treatment for opioid dependence. JAMA 267: 2750-2755.

Kalivas PW (2004). Glutamate systems in cocaine addiction. Curr Opin Pharmacol 4: 23-29.
Kimmel HL, Tallarida RJ, Holtzman SG (1997). Synergism between buprenorphine and cocaine on the rotational behavior of the nigrally-lesioned rat. Psychopharmacology 133: 372-377.

Kleber HD (2003). Pharmacologic treatments for heroin and cocaine dependence. Am J Addict 12: S5-S18.

Kosten TA, Marby DW, Nestler EJ (1991). Cocaine conditioned place preference is attenuated by chronic buprenorphine. Life Sci 49: PL201-PL206.

Kosten TR (1989). Pharmacotherapeutic interventions for cocaine abuse. Matching patients to treatments. J Nerv Mental Dis 177: 379-389.

Kosten TR (1990). Current pharmacotherapies for opioid dependence. Psychopharm Bull 26: 69-74.

Kosten TR, Rounsaville BJ, Kleber HD (1987). A 2.5-year follow-up of cocaine use among treated opioid addicts. Have our treatments helped? Arch Gen Psychiatry 44: 281-284.

Kosten TR, Rounsaville BJ, Kleber HD (1988). A 2.5 year follow-up of abstinence and relapse to cocaine abuse in opioid addicts. NIDA Res Monogr 81: 231-236.

Krantz MJ, Mehler PS (2004). Treating opioid dependence. Growing implications for primary care. Arch Intern Med 164: 277-288.

Leri F, Bruneau J, Stewart J (2003). Understanding polydrug use: review of heroin and cocaine co-use. Addiction 98: 7-22.

Leri F, Flores J, Rodaros D, Stewart J (2002). Blockade of stressinduced but not cocaine-induced reinstatement by infusion of noradrenergic antagonists into the bed nucleus of the stria terminalis or the central nucleus of the amygdala. J Neurosci 22: 5713-5718.

Leri F, Stewart J (2001). Drug-induced reinstatement to heroin and cocaine seeking: a rodent model of relapse in polydrug use. Exp Clin Psychopharmacol 9: 297-306.

Leri F, Tremblay A, Sorge RE, Stewart J (2004). Methadone maintenance reduces heroin- and cocaine-induced relapse without affecting stress-induced relapse in a rodent model of poly-drug use. Neuropsychopharmacology 29: 1312-1320.

Ling W, Charuvastra C, Collins JF, Batki S, Brown Jr LS, Kintaudi P et al (1998). Buprenorphine maintenance treatment of opiate dependence: a multicenter, randomized clinical trial. Addiction 93: 475-486.

Ling W, Wesson DR, Charuvastra C, Klett CJ (1996). A controlled trial comparing buprenorphine and methadone maintenance in opioid dependence. Arch Gen Psychiatry 53: 401-407.

Lukas SE, Mello NK, Drieze JM, Mendelson JH (1995). Buprenorphine-induced alterations of cocaine's reinforcing effects in rhesus monkey: a dose-response analysis. Drug Alcohol Depend 40: 87-98.

Martin G, Ahmed SH, Blank T, Spiess J, Koob GF, Siggins GR (1999). Chronic morphine treatment alters NMDA receptormediated synaptic transmission in the nucleus accumbens. J Neurosci 19: 9081-9089.

Martin G, Przewlocki R, Siggins GR (1999). Chronic morphine treatment selectively augments metabotropic glutamate receptor-induced inhibition of $N$-methyl-D-aspartate receptormediated neurotransmission in nucleus accumbens.J Pharmacol Exp Ther 288: 30-35.

Matthews RT, German DC (1984). Electrophysiological evidence for excitation of rat ventral tegmental area dopamine neurons by morphine. Neuroscience 11: 617-625.

McFarland K, Lapish CC, Kalivas PW (2003). Prefrontal glutamate release into the core of the nucleus accumbens mediates cocaineinduced reinstatement of drug-seeking behaviour. J Neurosci 23: 3531-3537.

Mello NK, Kamien JB, Lukas SE, Mendelson JH, Drieze JM, Sholar JW (1993). Effects of intermittent buprenorphine administration on cocaine self-administration by rhesus monkeys. J Pharmacol Exp Ther 264: 530-541. 
Mello NK, Lukas SE, Kamien JB, Mendelson JH, Drieze J, Cone EJ (1992). The effects of chronic buprenorphine treatment on cocaine and food self-administration by rhesus monkeys. J Pharmacol Exp Ther 260: 1185-1193.

Mello NK, Negus SS (1998). The effects of buprenorphine on selfadministration of cocaine and heroin 'speedball' combinations and heroin alone by rhesus monkeys. J Pharmacol Exp Ther 285: 444-456.

Montoya ID, Gorelick DA, Preston KL, Schroeder JR, Umbricht A, Cheskin LJ et al (2004). Randomized trial of buprenorphine for treatment of concurrent opiate and cocaine dependence. Clin Pharmacol Ther 75: 34-48.

Nestler EJ (2004). Historical review: molecular and cellular mechanisms of opiate and cocaine addiction. Trends Pharmacol Sci 25: 210-218.

Plunkett LM, Seifen E, Kennedy RH (1989). Effects of morphine pretreatment on cocaine cardiotoxicity in anesthetized guineapigs. Arch Int Pharmacodyn Ther 297: 60-67.

Ritz MC, Cone EJ, Kuhar MJ (1990). Cocaine inhibition of ligand binding at dopamine, norepinephrine and serotonin transporters: a structure-activity study. Life Sci 46: 635-645.

Ritz MC, Lamb RJ, Goldberg SR, Kuhar MJ (1988). Cocaine selfadministration appears to be mediated by dopamine uptake inhibition. Prog Neuropsychopharmacol Biol Psychiatry 12: 233-239.

Rothman RB, Baumann MH (2003). Monoamine transporters and psychostimulant drugs. Eur J Pharmacol 479: 23-40.

Schottenfeld RS, Pakes J, Ziedonis D, Kosten TR (1993). Buprenorphine: dose-related effects on cocaine and opioid use in cocaine-abusing opioid-dependent humans. Biol Psychiatry 34: 66-74.

Schottenfeld RS, Pakes JR, Oliveto A, Ziedonis D, Kosten TR (1997). Buprenorphine $v s$ methadone maintenance treatment for concurrent opioid dependence and cocaine abuse. Arch Gen Psychiatry 54: 713-720.

Shaham Y, Rajabi H, Stewart J (1996). Relapse to heroin-seeking in rats under opioid maintenance: the effects of stress, heroin priming, and withdrawal. J Neurosci 16: 1957-1963.
Shaham Y, Stewart J (1996). Effects of opioid and dopamine receptor antagonists on relapse induced by stress and reexposure to heroin in rats. Psychopharmacology 125: 385-391.

Smith MA, Gordon KA, Craig CK, Bryant PA, Ferguson ME, French $\mathrm{AM}$ et al (2003). Interactions between opioids and cocaine on locomotor activity in rats: influence of an opioid's relative efficacy at the mu receptor. Psychopharmacology 167: 265-273.

Stewart J (2000). Pathways to relapse: the neurobiology of drugand stress-induced relapse to drug-taking. J Psych Neurosci 25: $125-136$.

Stewart J (2003). Stress and relapse to drug seeking: studies in laboratory animals shed light on mechanisms and sources of long-term vulnerability. Am J Addict 12: 1-17.

Strain EC, Stitzer ML, Liebson IA, Bigelow GE (1994a). Buprenorphine versus methadone in the treatment of opioid-dependent cocaine users. Psychopharmacology 116: 401-406.

Strain EC, Stitzer ML, Liebson IA, Bigelow GE (1994b). Comparison of buprenorphine and methadone in the treatment of opioid dependence. Am J Psychiatry 151: 1025-1030.

Strain EC, Stitzer ML, Liebson IA, Bigelow GE (1996). Buprenorphine versus methadone in the treatment of opioid dependence: self-reports, urinalysis, and addiction severity index. J Clin Psychopharmacol 16: 58-67.

Tassiopoulos K, Bernstein J, Heeren T, Levenson S, Hingson R, Bernstein E (2004). Hair testing and self-report of cocaine use by heroin users. Addiction 99: 590-597.

Tzschentke TM (2002). Behavioral pharmacology of buprenorphine, with a focus on preclinical models of reward and addiction. Psychopharmacology 161: 1-16.

Tzschentke TM (2004). Reassessment of buprenorphine in conditioned place preference: temporal and pharmacological considerations. Psychopharmacology 172: 58-67.

Walsh SL, Eissenberg T (2003). The clinical pharmacology of buprenorphine: extrapolating from the laboratory to the clinic. Drug Alcohol Depend 70: S13-S27.

Walsh SL, Preston KL, Stitzer ML, Cone EJ, Bigelow GE (1994). Clinical pharmacology of buprenorphine: ceiling effects at high doses. Clin Pharmacol Ther 55: 569-580. 